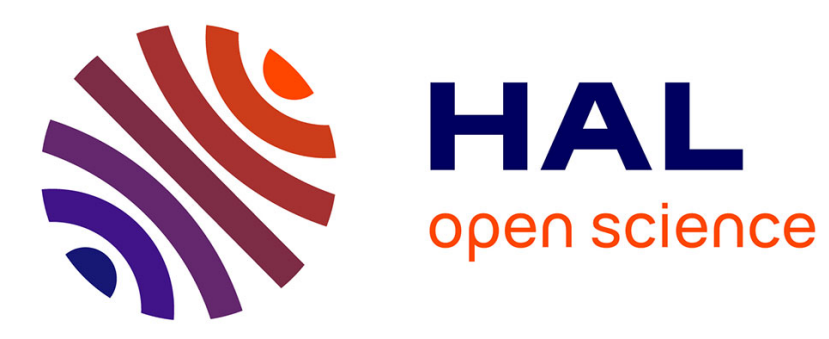

\title{
Experiments and FEM simulations of milling performed to identify material parameters
}

Aurélien Maurel-Pantel, Michael Fontaine, Jean-Claude Gelin, Gérard Michel, Sébastien Thibaud

\section{- To cite this version:}

Aurélien Maurel-Pantel, Michael Fontaine, Jean-Claude Gelin, Gérard Michel, Sébastien Thibaud. Experiments and FEM simulations of milling performed to identify material parameters. International Journal of Material Forming, 2008, 1 (suppl. 1), pp.1435-1438. 10.1007/s12289-008-0106-0 . hal00418876

\section{HAL Id: hal-00418876 https://hal.science/hal-00418876}

Submitted on 13 Dec 2021

HAL is a multi-disciplinary open access archive for the deposit and dissemination of scientific research documents, whether they are published or not. The documents may come from teaching and research institutions in France or abroad, or from public or private research centers.
L'archive ouverte pluridisciplinaire HAL, est destinée au dépôt et à la diffusion de documents scientifiques de niveau recherche, publiés ou non, émanant des établissements d'enseignement et de recherche français ou étrangers, des laboratoires publics ou privés. 


\title{
Experiments and FEM Simulations of Milling Performed to Identify Material Parameters
}

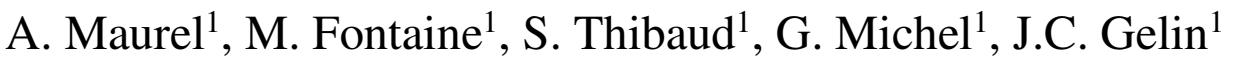 \\ ${ }^{1}$ FEMTO-ST Institute Applied Mechanics department LMARC - 24 chemin de l'épitaphe, 25000 Besançon, \\ France \\ URL: $\underline{w w w . f e m t o-s t . f r}$ \\ e-mail: aurelien.maurel@gmail.fr
}

\begin{abstract}
An inverse method of identification for the determination of material parameters that are used for the FEM simulation of milling processes is proposed. First of all, a special device has been instrumented and calibrated to perform force and torque measures, directly during milling experiments in using a piezoelectric dynamometer and a high frequency charge amplifier. The experimental results were saved and low pass filtered to obtain a data measured basis reliable and accurate. Then FEM simulations of milling were performed using explicit ALE based FEM code. The material behaviour is firstly described from a JohnsonCook constitutive law and different characterization test have been lead in a wide range of conditions to be use to identify a new behaviour law adapted to the process. A fracture model was also added to consider chip formation and separation. Finally, identification procedures are proposed for the determination of material law parameters. These procedures are based on an objective function to minimize, firstly defined by the experimental and numerical results obtained in the turning process and secondly by the experimental and analytical results obtained in milling process. The identification approach is mainly based on the Surfaces Response Method in the material parameters space, coupled to a sensitivity analysis. A Moving Least Square Approximation method is used to accelerate the identification process. This method of identification is here applied for a 304L stainless steel and the first investigations are presented.
\end{abstract}

Key words: FEM, Orthogonal cutting, Milling, 304L Material, Identification, Cutting forces measurements.

\section{INTRODUCTION}

Machining has become one of the most used processes in macro and micro manufacturing with applications in aeronautic, automotive or mechanical engineering industries. The understanding of the physical phenomena and the identification of material behaviour in machining are the main issue for the industrial process optimization. Some analytical models were previously proposed by Merchant [1] which was developed by Oxley [2] and Molinari \& Dudzinski [3], these last works were adapted to milling [4]. More recently, calibrated FEM models appear and seem to progress in the way of the real machining process simulation, Pantalé [5]. Nevertheless, these models give only a partial interpretation of the process's phenomena. To improve predictive capacity of these models, one needs to characterize the material behaviour which is involved in the machining process. Therefore it is emphasized in the present paper to proceed by an inverse method [6] [7] [8] based on FEM or analytical models for the identification of material parameters from machining experiments.

\section{NUMERICAL SIMULATION OF MACHINING}

\subsection{Numerical simulation of turning}

In order to perform numerical simulation of machining, a finite element model was implemented in LSDyna $\odot$ FEM code. As machining is an high speed metal forming process characterized by large dynamic stresses and localized high strains, an explicit code solution scheme was adopted. LS-Dyna@ FEM code has been chosen to build a Design of Experiment (DOE) empirical model of machining process in order to be able to identify and to understand process parameters. The final aim consists to obtain a reliable simulation of milling that is one of the more complex cutting processes. At the beginning, orthogonal cutting process has been studied to compare results with bibliography data. In a first stage, a $2 \mathrm{D}$ orthogonal cutting model has 
been developed with LS-Dyna $\odot$ FEM code. Secondly, with these first results in 2D, a 3D oblique cutting model has been developed to improve the simulation and to correspond to results obtained by Pantalé [5]. The figure 1 relates the distribution of von Mises effective stress contours from simulation results. All this data in orthogonal cutting conditions has shown that LS-Dyna $\odot$ is well adapted to create complex FEM numerical model as milling process.

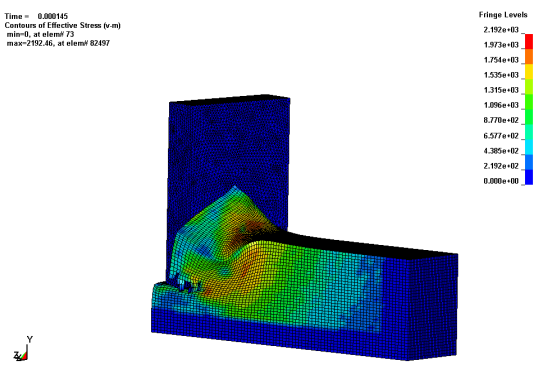

Fig. 1. Von Mises stress contours arising through FEM simulation of orthogonal cutting.

\subsection{Numerical simulation of milling}

Accordingly with the experiments presented in the following part, a $\varnothing 6 \mathrm{~mm}$ end mill and a 304L stainless steel rectangular specimen have been designed with SolidWorks $@$, and furthermore realist cutting conditions have been used in the numerical FEM model. Figure 2 relates the first simulation results. The test specimen is meshed with 260,000 elements. The corresponding material behaviour has been firstly modelled using the classical Johnson and Cook constitutive model (1) [9] whose the parameters are provided by the CETIM foundation.

$\sigma=\left[A+B\left(\varepsilon^{p}\right)^{n}\right]\left[1+C \ln \left(\frac{\dot{\varepsilon}^{p}}{\dot{\varepsilon}_{0}}\right)\right]\left[1-\left(\frac{T-T_{f}}{T_{\text {seuil }}-T_{f}}\right)^{m}\right](1)$

The end mill is meshed with about 100,000 elements and considered as a rigid body. This model uses an element failure criterion based on a limiting plastic strain critical value. The calculation time is about 10 days on a bi-processor Xeon 3.21GHz.
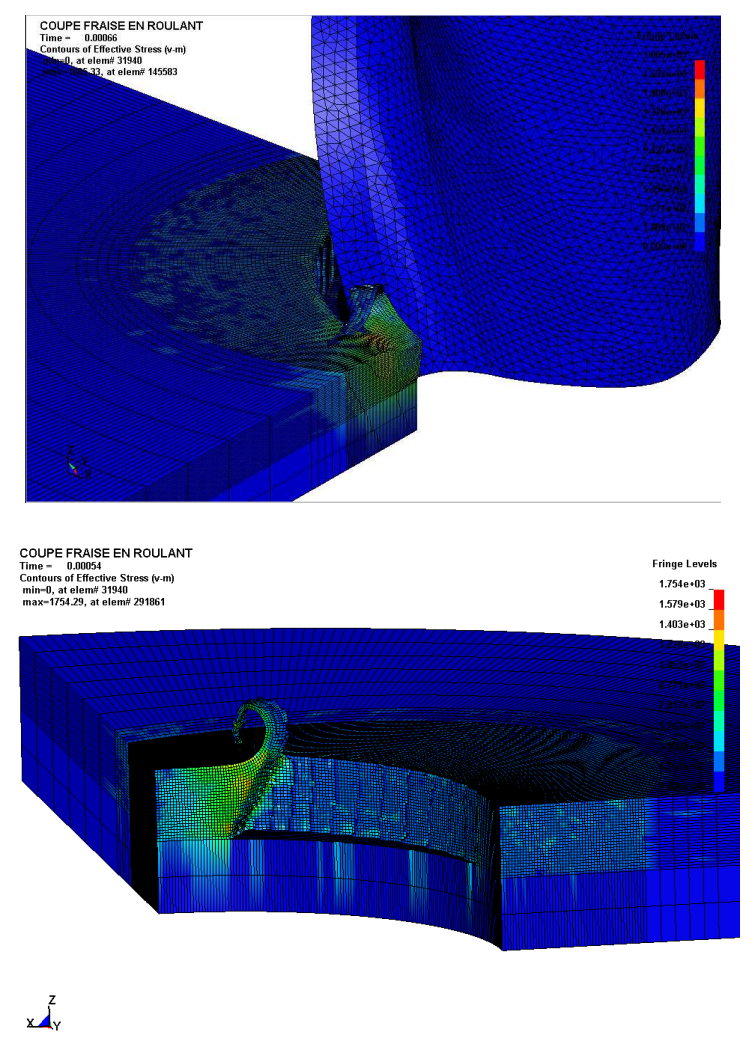
Fig. 2. Von Mises stress contours obtained through simulation results of a milling process numerical model with LS-Dyna software. The cutting conditions are $\mathrm{N}=20000 \mathrm{rpm} ; \mathrm{ft}=0,3 \mathrm{~mm} / \mathrm{tooth} ; \mathrm{Vc}=250 \mathrm{~m} / \mathrm{min}$.

\section{EXPERIMENTAL INVESTIGATIONS}

\subsection{Cutting forces measures during milling}

In the first step, a complete instrumentation including sensors and on line measuring system has been set up to obtain repetitive and reliable data. The sensor system is based on a Kistler ${ }^{\circledR}$ dynamometer using the piezoelectric accelerometers technology, in order to give, through direct measurement, the cutting forces during the machining process. The experiments were carried out on a KERN@ micro milling machine as shown in Figure 3. The dynamometer was fixed on the table of the 3 axes CNC machine, and then it was linked to the charge amplifier which was connected to a PC through an input/output acquisition card. The equipments chosen for these milling experiments are as following.

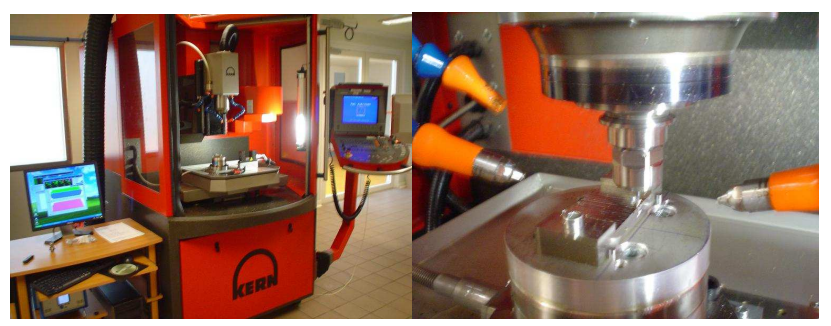

Fig. 3. Experimental data acquisition system used in milling

The types of the selected milling tools are two or four teeth end mills. These tools are uncoated tungsten carbide mills with $30^{\circ}$ nominal helix angle and $12^{\circ}$ normal rake angle, and the tested diameters are in the range 2-6 $\mathrm{mm}$. All the test specimens have been machined in the same 304L austenitic stainless steel bar and in the same dimensions: $80 \mathrm{~mm}$ x $40 \mathrm{~mm}$ x $10 \mathrm{~mm}$. All milling experiments have been carried out with a micro lubrication sprayed on the tooling area. The cutting velocities are defined between 50 and 400 m.min-1 to reach a maximum spindle speeds corresponding to $40000 \mathrm{rpm}$.

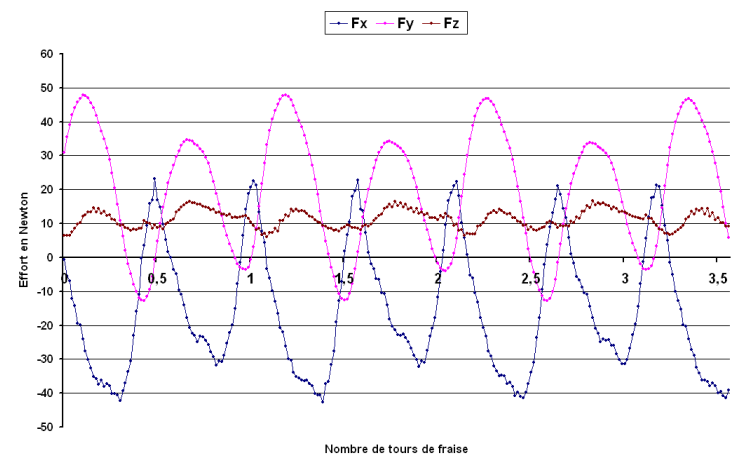

Fig. 4. Cutting forces $F_{x}, F_{y}, F_{z}$ vs. end mill rotations.

Figure 4 relates a zoom of the cutting forces stabilized signal in milling where the cutting conditions and machining parameters correspond to:

- 2 teeth end mill $\varnothing 4 \mathrm{~mm}$ in slotting tests (full radial immersion);

- Spindle speed: $\Omega=15920 \mathrm{rpm}$; Feed: $\mathrm{ft}=0.01 \mathrm{~mm} / \mathrm{tooth}$; Cutting speed: Vc $=200 \mathrm{~m} / \mathrm{min}$; Axial depth of cut: da $=0.5 \mathrm{~mm}$.

Figure 4 shows that is possible to get a good and accurate variation of the milling forces on the 3 machine axes. A signal spectral analysis was conducted on forces components in order to check the stability of measured data and to recover the equivalent forces for a rigid case after appropriate low filtering. These accurate and reliable measures allow the understanding of a part of the end mill behaviour during the milling process and then the setting up of the identification process. 


\section{BEHAVIOUR LAW OF THE 304L STAINLESS STEEL}

In the same time, tensile tests have been performed in the laboratory on the 304L stainless steel provided by CETIM Research Center. These first experiments permit to identify the material parameters of the JohnsonCook constitutive law (1). This model is based on tensile tests with low speed strain rate. The material parameters are identified by a genetic algorithm applied at the experiments results. Then to improve this identified model, new tests in partnership with other laboratories of the PGV national project will be realize with high speed strain rate and a wide range of temperature. O. Lurdos in Saint Etienne has been realised high speed strain rate torsion tests, and X. Soldani in Metz has been realised double shearing tests and Hopkinson bar tests. A generalized Voce type constitutive law has been identified by O. Lurdos and we will propose a new model adapted to the high speed strain to reach milling cutting conditions. This model will be based on the project rheological tests and identified with the numerical simulation of these tests.

The final aim of this work consists to propose a new behaviour law adapted to the machining process, to obtain a first set of parameters in order to simplify the identification procedure, then to implement this law in the FEM code and to compare the experimental characterization with the inverse identification method results presented in the next part.

\section{INVERSE IDENTTFICATION METHOD}

The final aim of this work consists to lead an inverse identification procedure for the determination of 304L stainless steel parameters of the behaviour law. The identification procedure methodology needs an objective function to minimize, a set of parameters to analyze, a finite element method or analytical solver and a procedure for updating the material parameters. In front of the too big calculation time of the milling simulation, the numerical methodology will be test on the oblique cutting simulation and on cutting forces measures in turning, to prove the feasibility of the method on milling process.

$$
R(\mathbf{p})=\sum_{\text {efforts.mesurés.n }} \frac{1}{2}\left(\sum_{i=1}^{N p}\left[F_{n}^{\exp }-F_{n}^{\text {num }}(\mathbf{p})\right]^{2}\right)
$$

For the milling experiments identification, the parameters system $\mathrm{p}\left(\mathrm{A}, \mathrm{B}, \mathrm{n}, \mathrm{C}, \mathrm{T}_{\text {seuil }}, \mathrm{m}\right)$ has been chosen in the Johnson-Cook constitutive law (1). Then an objective function dependent of the measured experimental criteria (cutting forces) has been defined in (2). The previous function measures difference between the cutting forces curves obtained with the numerical or analytical simulation software and with the experimental device. Figure 5 schematcal s s based on a set of parameters obtain through simulation

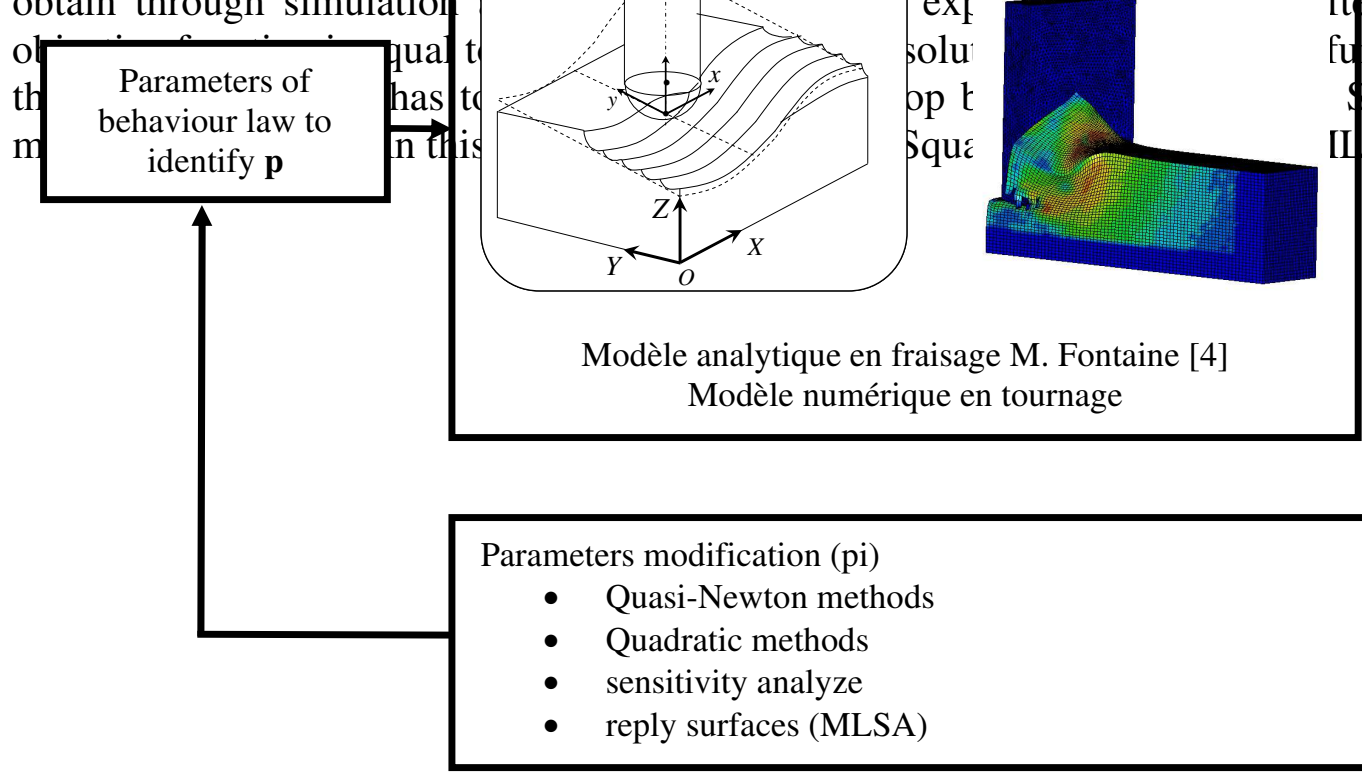

Fig. 5. Diagram representing the inverse identification procedures. 


\section{CONCLUSIONS}

Milling experiments allowed us to analyze accurately the measured cutting forces curves and to obtain reliable and useful measured data for the identification procedure. Then, a first 3D simulation of milling process has been set up in realist experiments conditions. The numerical model is based on a dynamic transient explicit scheme and on lagrangian formulation. The numerical cutting forces obtained give good results in matter of forces value and curves shape, but we will set up soon simulation with industrial tool to compare numerical and experimental results. At the end, this paper described the identification procedure which will be set up on analytical milling or numerical turning models. Moreover, further developments are in progress and concern the numerical model improvements, the identification of a new material behaviour model and the set up of cutting forces measures in turning in order to identify a friction law and to begin the identification procedure.

\section{ACKNOWLEDGEMENTS}

This work has been carried out with the financial support from the CETIM Foundation in the frame of PGV1 national project.

\section{REFERENCES}

1. E. Merchant, Basic mechanics of the metal cutting process, J. of Applied Mechanics, 66, (1944) 168-175.

2. P.L.B. Oxley, Mechanics of metal cutting, ASME, (1963) 50-60.

3. A. Molinari, D. Dudzinski, Stationary shear band in high speed machining, C.R. Acad. Sciences Paris, 315 (II), (1992) $399-$ 405.

4. M. Fontaine, A. Devillez, A. Moufki and D. Dudzinski, Predicitve force model for ball end milling and experimental validation with a wavelike form machining test, Int. J. Machine Tools and Manufacture, 46, (2006) 367-380.

5. O. Pantalé, "Modélisation et simulation tridimensionnelle de la coupe des métaux", Ph.D. Thesis, Bordeaux I University, 1996.

6. J.C. Gelin, C. Labergere, Application of optimal design and control strategies to the hydroforming of thin walled metallic tubes, Int. J. Forming Processes, 7, (2004) 141-158.

7. O. Ghouati, J.C. Gelin, Identification of material parameters directly from metal forming processes, J. Material Processing Technology, 80-81, (1998) 560-564.

8. O. Ghouati, J.C. Gelin, A finite element based identification method for complex material behaviours, Computational Materials Science, 21, (2001) 57-68.

9. G.R. Johnson, W.H. Cook, Constitutive model and data for metals subjected to large strains, high strain rates, and high temperatures, Proc. 7th Symp. On Ballistics, Netherlands(1983). 